\title{
ESTUDO ANATOMOPATOLÓGICO DE ALEVINOS DE JUNDIÁ INFECTADOS EXPERIMENTALMENTE POR Ichthyophtirius multifiliis E SUBMETIDOS A TRATAMENTOS CONVENCIONAIS
}

\section{(Pathological study of jundia fingerlings experimentally infected by ich and submitted to conventional treatments)}

\author{
CARNEIRO, P.C.F.'; CIRIO, S.M. ${ }^{2}$; SCHORER, M. ${ }^{3}$
}

\author{
${ }^{1}$ PUCPR - Pscicultura; \\ ${ }^{2}$ PUCPR - Patologia Veterinária; \\ ${ }^{3}$ Mestranda do Centro de Agricultura, UNESP - Jaboticabal, SP.
}

\begin{abstract}
The white spot disease is caused by Ichthyophthirius multifiliis (ich), a ciliated parasite characterized by its relatively large size, compared to other protozoans. Ich, one of the most devastating parasites affecting jundia culture, may destroy entire populations within a few hours. This study evaluated the histological effect of ich infection under some conventional treatments on jundia fingerlings. Fifteen fish $(3-6 \mathrm{~cm})$ were placed in 21 aquaria $(10 \mathrm{~L})$ for 5 days. The following treatments were used: $\mathrm{C} 1$ : non infected control; C2: infected control; F: formalin $(0.2$ $\mathrm{ml} / \mathrm{L}) ; \mathrm{M}$ : malachite green $(0.1 \mathrm{ml} / \mathrm{L})$; and $\mathrm{S}: \mathrm{NaCl} 1 \%$ $(10 \mathrm{~g} / \mathrm{L})$. The treatments were used as 3 baths of $1 \mathrm{~h}$ between intervals of $48 \mathrm{~h}$. Total mortality of $\mathrm{F}$ fish occurred within $48 \mathrm{~h}$, showing that formalin was toxic to jundia under concentration recommended for parasite treatment of most tropical fish species. The lowest mortality rate (33\%) was observed for S fish. The histological evaluation showed that ich caused hyperemia and hyperplasia of gill cells surrounding the parasite. At $96 \mathrm{~h}$, trophozoites were observed with the help of microscope $(40 \mathrm{x})$ under the skin of $\mathrm{C} 1$ fish. Ich was not visible to the naked eye on $\mathrm{C} 1 \mathrm{fish}$ at the beginning of the experimental period. Tomites, a young stage of ich, burrowed into the skin of jundia, penetrated the subepithelial layer and caused damage. Upper layers of skin were sloughed off within $96 \mathrm{~h}$ from fish of all treatments, except S fish. Ich irritates fish tissues, mainly the gill cells, and causes high mortality rate within a very short period of time. Additionally, the employed therapeutic treatments cause adverse changes to different levels of severity, mainly on the gill tissue.
\end{abstract}

Key-words: Rhamdia quelen, Ichthyophtirius multifiliis, pathology, histology.

RESUMO - A "doença dos pontos brancos" é causada pelo parasita ciliado Ichthyophthirius multifiliis caracterizado pelo seu tamanho relativamente grande quando comparado a outros protozoários. 0 ictio é responsável pelas maiores perdas observadas na criação do jundiá, podendo destruir toda a população de um viveiro em poucas horas. 0 presente estudo avaliou e descreveu as alterações patológicas macro e microscópicas causadas pelo ictio em alevinos de jundiá submetidos a tratamentos terapêuticos convencionais. Quinze peixes $(3-6 \mathrm{~cm})$ foram estocados em 21 aquários (10 L) e submetidos por cinco dias aos seguintes tratamentos: C1: controle não infectados; C2: controle infectados; F: formalina comercial $(0,2 \mathrm{ml} / \mathrm{I})$; $\mathrm{M}$ : verde malaquita $(0,1 \mathrm{ml} / \mathrm{l})$; e $\mathrm{S}$ : cloreto de sódio $1 \%(10 \mathrm{~g} / \mathrm{l})$. Foram realizados três banhos com duração de uma hora e intervalos de 48 horas. Mortalidade total foi observada nos exemplares expostos a formalina por 48 horas, mostrando que alevinos de jundiá são sensíveis a esse produto na concentração recomendada para a maioria das espécies tropicais. A menor taxa de mortalidade (33\%) foi registrada para os peixes submetidos ao sal. As análises histológicas denunciaram a presença de hiperemia e hiperplasia nas células do epitélio branquial próximas ao parasita. No grupo $\mathrm{C} 1$ foi registrada a presença de trofozoítos nos peixes coletados em 96 horas, sendo que os parasitas não foram observados naqueles peixes, a olho nu, no início do experimento. Tomitos, a forma jovem do parasita, alojaram-se na pele com localização subepidermal e causando lesões. Foi verificada irritação causada pelo ictio em diferentes níveis e em todos os tratamentos, principalmente nas células do epitélio branquial. Próximo ao final do período experimental foi observada esfoliação da pele de peixes de todos os tratamentos, exceto nos peixes submetidos ao sal comum. A infecção pelo ictio ocorre de forma muito rápida e intensa, causando alterações anatomopatológicas severas no tecido branquial e altas taxas de mortalidade em curto período de tempo. Adicionalmente, os tratamentos terapêuticos empregados causam reações adversas no jundiá em graus variados de severidade, principalmente no tecido branquial.

Palavras-chave: Rhamdia quelen, Ichthyophtirius multifiliis, patologia, histologia. 


\section{Introdução}

Ichthiophtirius multifiliis, ou ictio como é conhecido popularmente, é um ectoparasita obrigatório que, por definição, necessita de um hospedeiro para complementar seu ciclo de vida. É um protozoário do grupo dos cilióforos que se instala principalmente nas brânquias e demais tecidos do peixe, provocando lesões e se alimentando de suco tissular, secreções, fragmentos de células epidérmicas e sangue, causando o que se conhece por "doença dos pontos brancos". A epidemia acontece mais freqüentemente nos peixes tropicais de cativeiro após queda brusca de temperatura. Ao ser infectado, o peixe tende a se atritar nas laterais do viveiro, provocando lesões cutâneas e elevando a secreção de muco, responsável pela impermeabilização da pele que, quando em excesso nas brânquias, pode dificultar as trocas gasosas (EIRAS, 1994). As injúrias, por sua vez, contribuem para o aparecimento de infecções secundárias elevando as chances de ocorrência de altas taxas de mortalidade (PAVANELLI et al., 1998). Todos os peixes de água doce são suscetíveis à infecção pelo ictio, mas espécies sem escamas como os bagres são particularmente vulneráveis, podendo apresentar $100 \%$ de mortalidade em poucos dias (NOGA, 1996).

O jundiá (Rhamdia quelen) é um peixe de rápido crescimento e que pode ser facilmente criado em cativeiro. No sul do Brasil, a sua criação vem aumentando devido à sua adaptação às condições climáticas, apresentando boa aceitação pelo mercado consumidor tanto no segmento da pesca esportiva quanto para a alimentação direta (CARNEIRO et al., 2002; BALDISSEROTTO e RADÜNZ NETO, 2004). Entre os desafios para o estabelecimento de um modelo para a criação desta espécie em cativeiro está o desenvolvimento de técnicas de controle do ictio, bem como o aumento do conhecimento sobre a relação parasita-hospedeiro, principalmente durante as primeiras semanas de vida do jundiá. Portanto, este estudo teve como objetivo a avaliação e descrição das alterações patológicas macro e microscópicas de alevinos de jundiá causadas pelo ictio em infecção experimental, bem como os efeitos de tratamentos terapêuticos convencionais sobre o parasita e sobre os peixes.

\section{Material e Métodos}

Foram utilizados 21 aquários de $10 \mathrm{~L}$ supridos de aeração individual feita por pedras porosas ligadas a um compressor. Os tratamentos empregados foram adaptados de CARNEIRO et al. (2005), sendo: C1: controle de peixes não infectados; C2: controle de peixes infectados; F: formalina comercial $(0,2 \mathrm{ml} / \mathrm{L})$; $\mathrm{M}$ : verde malaquita $(0,1 \mathrm{mg} / \mathrm{L})$; e $S$ cloreto de sódio $1 \%(10 \mathrm{~g} / \mathrm{L})$. Foram realizados três banhos com duração de uma hora e intervalos de 48 horas.

Cada tratamento teve três repetições, sendo que cada aquário recebeu 15 alevinos de jundiá com comprimento entre três e seis centímetros (50-60 dias; 3-5 gramas). A contaminação dos peixes foi feita pela introdução de alguns peixes portadores do ictio quando todos os animais experimentais ainda encontravam-se num mesmo recipiente. A distribuição dos peixes nas unidades experimentais, bem como o início do experimento, ocorreu quando foram observados macroscópicamente três a cinco pontos brancos na superfície cutânea da maioria dos peixes, caracterizando o início do processo infeccioso.

Foram coletados dois peixes de cada aquário após 48 horas de cada banho terapêutico para a contagem do número de parasitas e posterior análise histopatológica das brânquias e pele. Na última coleta (120 horas) todos os peixes remanescentes foram submetidos à contagem do número de parasitas em microscópio estereoscópico, sendo coletados mais exemplares para análises histopatológicas de brânquias e pele. O material coletado para a análise histopatológica foi fixado por 24 horas em solução de formol-ácido fórmico a $5 \%$ para descalcificação das brânquias. Cortes histológicos de cinco micrômetros foram corados pelas técnicas de Hematoxilina-Eosina, Tricrômico de Mallory, Tricrômico de Shorr e Azul de Toluidina, para posterior seleção de imagens e registro fotográfico.

A taxa de mortalidade cumulativa foi calculada pela retirada e contagem diária dos peixes mortos de cada aquário. $O$ ensaio experimental foi delineado de forma inteiramente casualizada. O número de parasitas observados e a mortalidade foram submetidos à análise de variância e as médias foram comparadas pelo teste de Tukey.

Durante o período experimental o oxigênio dissolvido, a temperatura e o $\mathrm{pH}$ foram monitorados diariamente, mantendo-se dentro da faixa adequada para a maioria das espécies de peixes tropicais $(6,0 \pm 0,63 \mathrm{mg} / \mathrm{L}$, $23,7^{\circ} \mathrm{C} \pm 3,9$ e $8,0 \mathrm{pH} \pm 0,26$, respectivamente).

\section{Resultados e Discussão}

Com exceção dos animais submetidos aos banhos com verde malaquita, os peixes dos demais tratamentos apresentaram infecção progressiva pelo ictio de acordo com as lesões observadas macroscópicamente no período de 96 horas pós-infecção, inclusive exemplares do grupo $\mathrm{C} 1$ (controle não infectado). Os peixes do tratamento com verde malaquita desenvolveram infecção de forma mais branda e, após o segundo banho, apresentaram diminuição do número de lesões cutâneas, não sendo mais observadas no final do período experimental. O número de pontos brancos observados nos peixes do grupo $M$ foi significativamente inferior $(P<0,05)$ aos dos demais tratamentos após 96 horas. Os peixes submetidos a banhos com cloreto de sódio apresentaram diminuição nas lesões cutâneas a partir do terceiro banho terapêutico (TABELA 1). Estudo anterior corrobora os resultados positivos desses dois produtos no controle da infecção do jundiá pelo ictio, 
Estudo anatomopatológico de alevinos de jundiá infectados experimentalmente por Ichthyophtirius multifiliis...

porém ressalta a importância de estudos adicionais que vislumbrem estratégias alternativas de prevenção e/ou controle desse parasita e que não apresentem as desvantagens do uso do verde de malaquita e do cloreto de sódio como a sua toxicidade e alto custo (quando utilizado em viveiros), respectivamente (CARNEIRO et al., 2005). PAVANELLI et al. (1998) enfatizam ainda que, de forma geral em criações intensivas nenhum tratamento parece ser eficaz quando a infecção é massiva e o diagnóstico tardio.

TABELA 1 - NÚMERO MÉDIO DE PARASITAS OBSERVADOS MACROSCOPICAMENTE E MORTALIDADE CUMULATIVA (\%) DE ALEVINOS DE JUNDIÁ RHAMDIA QUELEN SUBMETIDOS A TRATAMENTOS TERAPÊUTICOS CONVENCIONAIS. SÃO JOSÉ DOS PINHAIS, PR (2005).

\begin{tabular}{|c|c|c|c|c|c|c|c|c|}
\hline & \multicolumn{2}{|c|}{$24 \mathrm{~h}$} & \multicolumn{2}{|c|}{$48 \mathrm{~h}$} & \multicolumn{2}{|c|}{$96 \mathrm{~h}$} & \multicolumn{2}{|c|}{$120 \mathrm{~h}$} \\
\hline & $\begin{array}{l}\text { Número } \\
\text { de } \\
\text { parasitas }\end{array}$ & $\begin{array}{c}\text { Mortalidade } \\
(\%)\end{array}$ & $\begin{array}{l}\text { Número } \\
\text { de } \\
\text { parasitas }\end{array}$ & $\begin{array}{c}\text { Mortalidade } \\
(\%)\end{array}$ & $\begin{array}{c}\text { Número } \\
\text { de } \\
\text { parasitas }\end{array}$ & $\begin{array}{c}\text { Mortalidade } \\
(\%)\end{array}$ & $\begin{array}{l}\text { Número } \\
\text { de } \\
\text { parasitas }\end{array}$ & $\begin{array}{c}\text { Mortalidade } \\
(\%)\end{array}$ \\
\hline Controle sadio & $0^{b}$ & $7^{\mathrm{ab}}$ & $6^{b}$ & $20 \stackrel{a}{a}$ & $111^{a}$ & $67^{\underline{a}}$ & -- & $100^{\underline{a}}$ \\
\hline Controle infectado & 4 a & $2^{b}$ & $31 \stackrel{a}{a}$ & $9^{a b}$ & $128^{\mathrm{a}}$ & $78 \stackrel{\text { a }}{ }$ & $93^{a}$ & 96 a \\
\hline $\begin{array}{l}\text { Formalina } \quad(0,2 \\
\mathrm{mg} / \mathrm{L})\end{array}$ & $3 \stackrel{a}{a}$ & $2 \stackrel{a}{-}$ & $21 \stackrel{a}{=}$ & $33 \stackrel{a}{-}$ & $86 \stackrel{a}{-}$ & $76 \stackrel{a}{=}$ & -- & $100^{a}$ \\
\hline $\begin{array}{l}\text { Verde } \\
\text { malaquita } \\
\mathrm{mg} / \mathrm{L} \text { ) }\end{array}$ & $4 \stackrel{a}{a}$ & $11^{\mathrm{a}}$ & $8^{a b}$ & $40 \stackrel{a}{-}$ & $2^{b}$ & $64 \stackrel{\mathrm{a}}{ }$ & $0^{c}$ & $80 \stackrel{a}{=}$ \\
\hline $\begin{array}{l}\text { Cloreto de sódio } \\
(10 \mathrm{~g} / \mathrm{L})\end{array}$ & $4 \stackrel{a}{a}$ & $0^{b}$ & $28 \stackrel{\mathrm{a}}{ }$ & $0^{b}$ & $71 \stackrel{\mathrm{a}}{ }$ & $20^{b}$ & $37^{b}$ & $33^{b}$ \\
\hline
\end{tabular}

Letras diferentes na mesma coluna representam diferenças significativas $(P<0,05)$.

A análise histopatológica dos cortes de pele do jundiá mostrou trofontes de diferentes tamanhos localizados na região subepidermal. O ciclo de vida do ictio pode ser dividido em três fases, sendo a epidérmica a mais importante por ser aquela que causa a doença. A FIGURA 1 confirma a informação apresentada por PAVANELLI et al. (1998) que nessa fase os parasitas alojam-se entre a epiderme e a derme do peixe e conferem os pequenos pontos brancos observados macroscópicamente, com até um milímetro de diâmetro, caracterizando a instalação da doença. $O$ tamanho da lesão varia de acordo com o número de trofontes agrupados no mesmo local. Na FIGURA 2 observa-se que existem vários trofontes agrupados, sendo fácil a visualização macroscópica da lesão. Em alguns tratamentos observou-se ainda reação inflamatória adjacente ao parasita. PAVANELLI et al. (1998) afirmam que um dos danos da ictiofitiríase é o fato dos parasitas alimentarem-se de sucos tissulares e fragmentos de células epidermais causando lesões que podem se espalhar por todo o corpo dos peixes, pelas brânquias, e mais raramente, pela cavidade bucal.

FIGURA 1 - CORTE HISTOLÓGICO DA PELE DE JUNDIÁ Rhamdia quelen COM PRESENÇA DE ICTIO Ichthiophtirius multifillis NA FASE TROFONTE (SETA) COM LOCALIZAÇÃO SUBEPIDERMAL. (E) EPIDERME. (D) DERME. TRICRÔMICO DE SHORR. OBJETIVA 40X.

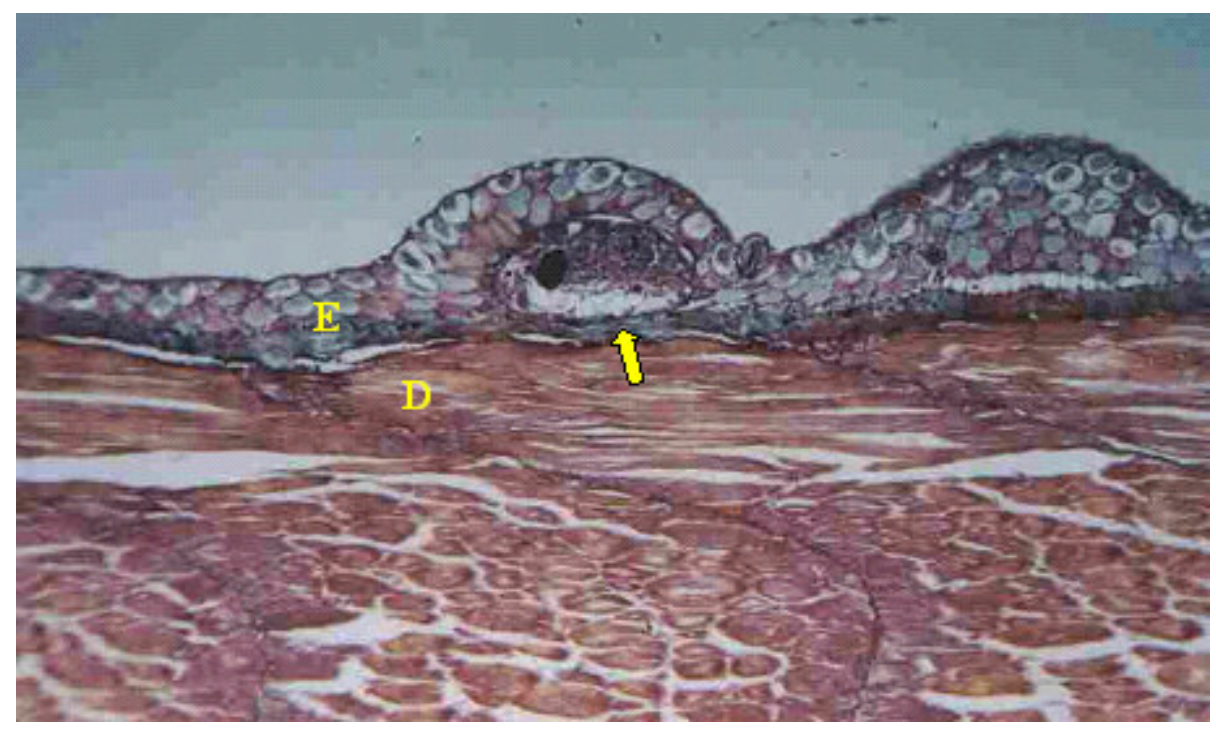






Foram encontrados parasitas em região subepidermal em peixes do grupo $\mathrm{C} 1$ controle não infectado, mesmo não tendo sido observados macroscopicamente pontos brancos indicativos da infecção cutânea no início do período experimental. Segundo POST (1987), os tomitos, fase infectante do ictio que penetraram na pele dos peixes, não são visíveis a olho nu, ressaltando a importância da manutenção de peixes vindo de outros locais em quarentena antes de sua introdução no ambiente de destino. De acordo com NOGA (1996) esses parasitas podem estar presentes de forma assintomática e desencadear a doença propriamente dita em condições desfavoráveis como após quedas bruscas da temperatura da água.

Nos cortes histológicos das brânquias dos peixes de todos os tratamentos foram observadas hiperemia e hiperplasia epitelial em lamelas secundárias nos locais de fixação dos trofontes. A intensidade das lesões provocadas pelos parasitas depende de vários fatores relacionados com o grupo do parasita em questão, a sua localização e o modo particular como atua sobre o hospedeiro. Como ocorre diminuição dos espaços interlamelares em função dos parasitas, limitando significativamente a área de superfície disponível para as trocas gasosas, o organismo do peixe reage aumentando o número de células epiteliais próximas para melhorar a captação de oxigênio (MOREIRA et al., 2001). Isso implica na diminuição ou perda da atividade respiratória podendo, nos casos mais graves, provocar a morte do hospedeiro por asfixia (ROUBAL et al., 1989). O incremento na secreção de muco no tecido branquial associado à infecção pelo ictio também prejudica o processo respiratório por aumentar a impermeabilização das brânquias e diminuir a capacidade de trocas gasosas (POST, 1987).

O aumento do número de lesões cutâneas observadas no período experimental confirma que o ciclo de vida do parasita se completa em até quatro dias ou 96 horas (EIRAS, 1994; PAVANELLI et al., 1998; KUBITZA e KUBITZA, 1999; MOREIRA et al., 2001). A mortalidade foi crescente em todos os tratamentos, sendo de $100 \%, 96 \%, 100 \%$ e $80 \%$ no final do período experimental para os tratamentos controle não infectado, controle infectado, formalina e verde malaquita, respectivamente. A menor taxa de mortalidade (33\%; $\mathrm{p}<0,05)$ foi observada no tratamento com cloreto de sódio 1\% a partir 96 horas, porém este tratamento não eliminou completamente a presença de pontos brancos nos peixes sobreviventes ao final do período experimental (TABELA 1). A verificação de taxas anormais de mortalidade é a percepção mais visível e imediata de muitas das parasitoses. No entanto, não é apenas este fato que deve preocupar o piscicultor, pois as conseqüências da parasitose não se manifestam apenas desse modo. Infecções secundárias são comumente associadas a ictiofitiríase pois, além das lesões deixadas pelo próprio ictio, o peixe infectado costuma esfregar-se nas paredes do viveiro facilitando ainda mais a entrada de outros agentes oportunistas, como fungos e bactérias que podem ser mais prejudiciais do que o próprio ictio (POST, 1987; PAVANELLI et al., 1998).

O cloreto de sódio é utilizado como tratamento curativo e também preventivo de diversas enfermidades em peixes (POST, 1987; PAVANELLI et al., 1998). Segundo NOGA (1996), algumas espécies de bagre são sensíveis a baixas concentrações de sal. Porém, este estudo mostra que o jundiá tolera banhos com $10 \mathrm{~g} / \mathrm{L}$ de 
Estudo anatomopatológico de alevinos de jundiá infectados experimentalmente por Ichthyophtirius multifiliis...

cloreto de sódio, apresentando apenas sinais leves de hiperemia e telangiectasia em brânquias no primeiro banho. A tolerância do jundiá ao cloreto de sódio a $1 \%$ garante boas perspectivas de controle de diversas patogenias que possuem esse produto como forma de tratamento por ser um produto de baixo custo (em se tratando de condições laboratoriais ou em pequenos tanques d'água) e de fácil aquisição, além de não apresentar restrições de uso ou necessitar de período de carência (EIRAS, 1994; KUBITZA e KUBITZA, 1999).

A formalina comercial mostrou-se tóxica ao jundiá na concentração recomendada para a maioria dos peixes tropicais (POST 1987; PAVANELLI et al., 1998; KUBITZA e KUBITZA, 1999). Neste estudo o tratamento com formalina causou morte contínua dos alevinos de jundiá nas primeiras 48 horas. Além disso, após o primeiro banho com formalina comercial, as brânquias de todos os peixes desse tratamento apresentaram hiperemia, telangiectasia e acentuada hiperplasia de células epiteliais de lamelas secundárias (FIGURA 3). Segundo NOGA (1996) e MOREIRA et al. (2001) estas lesões desenvolvem-se quando o ambiente aquático é impróprio e também sob ação de substâncias tóxicas. WARREN (1981) considera a formalina irritante para as brânquias e o óbito pode ocorrer dentro de 72 horas para algumas espécies. Ainda segundo esse último autor, acima de $27^{\circ} \mathrm{C}$ o uso da formalina é contra indicado, sendo que cada $5 \mathrm{mg} / \mathrm{l}$ de formalina remove $1 \mathrm{mg} / \mathrm{l}$ de oxigênio dissolvido da água. Como resposta da brânquia a essa agressão observa-se então hiperplasia epitelial acentuada nas lamelas secundárias, que pode levar à fusão das lamelas branquiais e conseqüente óbito por hipóxia ou anóxia (EIRAS, 1994; NOGA, 1996; KUBITZA e KUBITZA, 1999; MOREIRA et al, 2001).

O tratamento com verde malaquita apresentou mortalidade crescente dos alevinos até o fim do período experimental e foi maior do que aquela observada em estudo prévio (CARNEIRO et al., 2005). Os peixes deste grupo não apresentaram o parasita pelo corpo no final do período experimental, sendo observada apenas hiperemia moderada (FIGURA4). O verde de malaquita é efetivo contra protozoários ectoparasitas e tem sido muito utilizado por produtores de alevinos de jundiá para minimizar as perdas causadas pelo ictio, mesmo sabendo-se das restrições com relação ao uso desse produto, principalmente quando utilizado em peixes destinado ao consumo humano. O verde de malaquita é apontado como tóxico para bagres por BILLS et al. (1977), sendo sua toxicidade variável em função do estado de saúde do peixe, podendo ainda contribuir para a elevação da mortalidade quando aplicado em animais excessivamente estressados.

FIGURA 3 - BRÂNQUIAS DE JUNDIÁ Rhamdia quelen SUBMETIDOS A BANHOS COM FORMALINA COMERCIAL (0,2ml/L). HIPERPLASIA DE CÉLULAS EPITELIAIS DE LAMELAS SECUNDÁRIAS (H) E TELANGIECTASIA (SETA). TRICRÔMICO DE SHORR. OBJETIVA 40X.

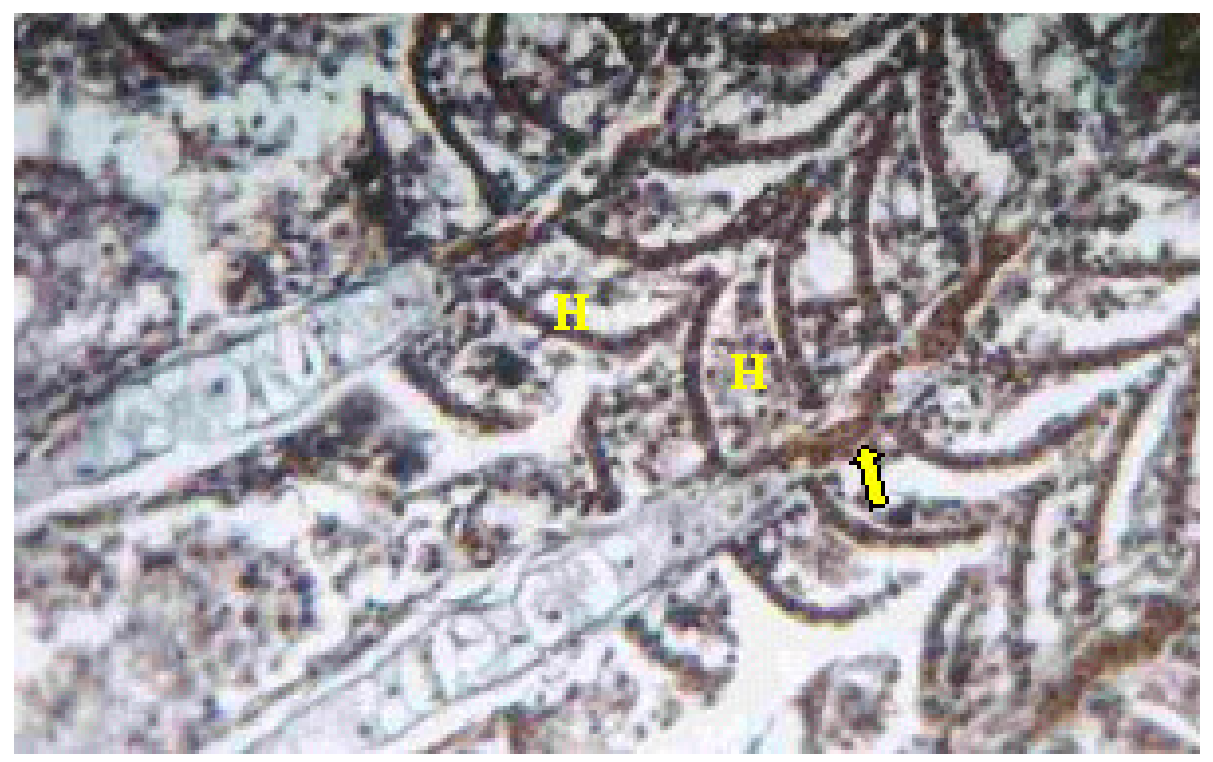


FIGURA 4 - BRÂNQUIAS DE JUNDIÁ Rhamdia quelen SUBMETIDOS A BANHOS COM VERDE DE MALAQUITA 0,1\%. TELAGIECTASIA (T). hEMATOXILINA-EOSINA. OBJETIVA 40X.

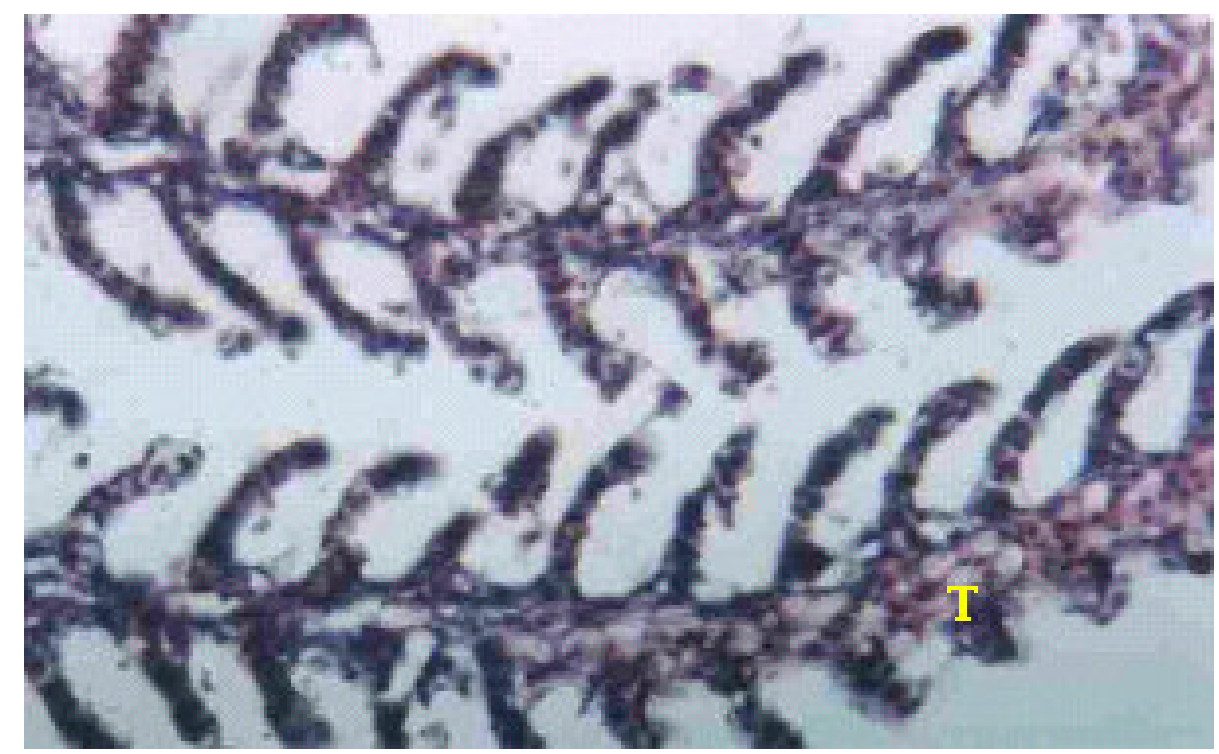

\section{Conclusões}

O presente trabalho permite concluir que:

1. O ictio causa alterações anatomo-patológicas severas no tecido branquial de alevinos de jundiá;

2. Apesar do efeito positivo do verde de malaquita na redução no número de parasitas, seu emprego pode causar altas taxas de mortalidade dos alevinos. Por outro lado, o $\mathrm{NaCl}$ apresenta efeito tardio e menos efetivo que o verde de malaquita na redução do número de parasitas, porém provoca menores taxas de mortalidade;

3. Os tratamentos terapêuticos empregados causam reações adversas em alevinos de jundiá em graus variados de severidade, principalmente no tecido branquial. Adicionalmente, o jundiá apresenta-se altamente sensível à formalina na concentração recomendada para a maioria das espécies tropicais. Ainda são necessários estudos que busquem alternativas eficazes e economicamente viáveis ao controle do ictio em jundiá.

\section{Referências}

BALDISSEROTTO, B.; RADÜNZ NETO, J. Criação de Jundiá. Editora UFSM, 2004. 232 p.

BILLS, T.D.; MARKING, L.L.; CHANDLER, J.H. Malachite green: its toxicity to aquaticorganisms, persistence and removal with activated carbon. United States Fish and Wildlife Service investigation in Fish Control, v.75, p.1-6, 1977.

CARNEIRO, P. C. F.; BENDHACK, F.; MIKOS, J. D.; SCHORER, M.; OLIVEIRA FILHO, P. R. C. Jundiá: Um grande peixe para a Região Sul. Panorama da Aqüicultura, v.12, p.41-46, 2002.
CARNEIRO, P.C.F.; SCHORER, M.; MIKOS, J.D. Tratamentos terapêuticos convencionais no controle do ectoparasita Ichthiophtirius mutifilis em jundiá Rhamdia quelen. Pesquisa Agropecuária Brasileira, v.40, p.99-102, 2005.

EIRAS, J.C. Elementos de ictioparasitologia. Fundação Antonio de Almeida, Porto, 1994. 339 p.

KUBITZA, F., KUBITZA, L.M.M. Principais parasitoses e doenças dos peixes cultivados. Jundiaí, 1999. 96 p.

MOREIRA, H.L.M.; VARGAS, L.; RIBERO, R.P.; ZIMMERMANN, S. Fundamentos da moderna aqüicultura. Editora da ULBRA, 2001. 199 p.

NOGA, E. J. Fish Disease: diagnostic and treatment. MosbyYear Book. Missouri, 1996. 367 p.

PAVANELLI, G.C.; EIRAS, J.C.; TAKEMOTO, R.M. Doenças de peixes - Profilaxia, diagnóstico e tratamento. EDUEM, 1998. 264 p.

POST, G Textbook of fish health. T.F.H. Publications, Neptune City, 1987. 288 p.

ROUBAL, F.R.; LESTER, R.J.G; FOSTER, C.K. Studies on cultured and gill attached Paramoeba sp. (Gymnamoebae; Paramoebidae) and the cytopathology of paramoebic gill disease in Atlantic salmon, Salmo solar L., from Tasmania. Journal of Fish Diseases, v.12, p.481-492, 1989.

WARREN, J. W. Disease of hatchery fish. US Fish and Wildlife Service, 1981. 91p.

Recebido para publicação: $\quad$ 10/02/2006 Aprovado: 